\title{
Migraine prevalence, disease burden, \\ CME \\ and the need for preventive therapy
}

\author{
R.B. Lipton, MD; M.E. Bigal, MD, PhD; M. Diamond, MD; F. Freitag, DO; M.L. Reed, PhD; \\ and W.F. Stewart, PhD; on behalf of the AMPP Advisory Group*
}

\begin{abstract}
Objectives: 1) To reassess the prevalence of migraine in the United States; 2) to assess patterns of migraine treatment in the population; and 3) to contrast current patterns of preventive treatment use with recommendations for use from an expert headache panel. Methods: A validated self-administered headache questionnaire was mailed to 120,000 US households, representative of the US population. Migraineurs were identified according to the criteria of the second edition of the International Classification of Headache Disorders. Guidelines for preventive medication use were developed by a panel of headache experts. Criteria for consider or offer prevention were based on headache frequency and impairment. Results: We assessed 162,576 individuals aged 12 years or older. The 1-year period prevalence for migraine was $11.7 \%$ (17.1\% in women and 5.6\% in men). Prevalence peaked in middle life and was lower in adolescents and those older than age 60 years. Of all migraineurs, $31.3 \%$ had an attack frequency of three or more per month, and 53.7\% reported severe impairment or the need for bed rest. In total, 25.7\% met criteria for "offer prevention," and in an additional 13.1\%, prevention should be considered. Just $13.0 \%$ reported current use of daily preventive migraine medication. Conclusions: Compared with previous studies, the epidemiologic profile of migraine has remained stable in the United States during the past 15 years. More than one in four migraineurs are candidates for preventive therapy, and a substantial proportion of those who might benefit from prevention do not receive it.
\end{abstract}

NEUROLOGY 2007;68:343-349

Migraine affects roughly $12 \%$ of the adults in occidental countries. ${ }^{1,2}$ In US population studies, the prevalence of migraine is approximately $18 \%$ in women and 6\% in men. ${ }^{3-5}$ Approximately $90 \%$ of the migraineurs have moderate or severe pain, three quarters have a reduced ability to function during the headache attacks, and one-third require bed rest during their attacks..$^{6-9}$

Migraine is also undertreated in the United States, though most studies have focused on acute treatment. ${ }^{6-9}$ Most migraineurs treat their headaches with acute treatments to the exclusion of preventive drugs. ${ }^{5,10,11}$ Patterns of use for migraine preventive treatment have rarely been studied in population samples.

The US Headache Consortium Guidelines discuss indications for the use of preventive medication, but do not provide operational criteria. ${ }^{12}$ Because attack frequency and medication overuse are risk factors for headache progression, it is pos- sible that preventive medication may also reduce the risk of progression. ${ }^{13-16}$

To better define the need for and patterns of use of preventive treatment, we conducted the American Migraine Prevalence and Prevention (AMPP) study. The AMPP aims to assess the epidemiology, the burden, and the patterns of treatment for migraine, using methods that allow comparisons with the findings of the American Migraine Studies I (AMS-I) and II (AMS-II)..$^{3-5}$ As part of this effort, an expert panel defined operational criteria for preventive treatment. This panel defined three groups in terms of their need for preventive treatment. The first group should be offered preventive treatment. In the second group, prevention should be considered; prevention was an option, though patients could reasonably decide not to use preventives. In the third group, prevention was not indicated. Operational definitions are provided in the Methods section.

Herein we describe the epidemiology of migraine

\section{Commentary, see page 319}

\footnotetext{
*The AMPP Advisory Group: Richard B. Lipton, MD (principal investigator); Marcelo E. Bigal, MD, PhD; Dawn Buse, MD; Michael L. Reed, PhD; Walter Stewart, PhD; Merle Diamond, MD; Frederick Freitag, DO; Elisabeth Hazard, PhD; Jonothan Tierce, CPhil; Elizabeth Loder, MD; Paul Winner, MD; Stephen Silberstein, MD; Suzanne Simons; and Seymour Diamond, MD.

From the Department of Neurology (R.B.L., M.E.B.) and Department of Epidemiology and Population Health (R.B.L.), Albert Einstein College of Medicine, Bronx, NY; The Montefiore Headache Center, Bronx, NY (R.B.L., M.E.B.); The New England Center for Headache, Stamford, CT (M.E.B.); Diamond Headache Center, Chicago, IL (M.D., F.F.); Vedanta Research, Chapel Hill, NC (M.L.R.); and Center for Health Research \& Rural Advocacy, Geisinger Clinic, Danville, PA (W.F.S.).

Disclosure: This study was sponsored by the National Headache Foundation through a grant from Ortho-McNeil Neurologics, Inc. Drs. Lipton, Bigal, Reed, Freitag, and Diamond have received grants and honoraria in excess of $\$ 10,000$ from Ortho-McNeil Neurologics Inc. Dr. Stewart has nothing to disclose. Received July 7, 2006. Accepted in final form October 4, 2006.

Address correspondence and reprint requests to Dr. Richard B. Lipton, The Albert Einstein College of Medicine, 1300 Morris Park Avenue, Bronx, NY, 10461; e-mail: rlipton@aecom.yu.edu
} 


\begin{tabular}{|c|c|c|c|c|}
\hline & $\begin{array}{c}\text { No. in total } \\
\text { population surveyed }\end{array}$ & $\begin{array}{c}\text { Distribution in } \\
\text { total population } \\
\text { surveyed, respondents }\end{array}$ & $\begin{array}{c}\text { No. of } \\
\text { respondents }\end{array}$ & Response rate, $\%$ \\
\hline \multicolumn{5}{|l|}{ Sex } \\
\hline Men & 124,665 & 48.4 & 77,185 & 62 \\
\hline Women & 132,674 & 51.6 & 85,571 & 64 \\
\hline \multicolumn{5}{|l|}{ Race } \\
\hline White & 217,501 & 84.5 & 140,948 & 65 \\
\hline Black & 21,307 & 8.3 & 11,950 & 56 \\
\hline Asian, Pacific Islander & 3,898 & 1.5 & 1,923 & 49 \\
\hline American, Indian & 1,791 & 0.7 & 1,019 & 56 \\
\hline Other & 4,707 & 1.8 & 2,071 & 44 \\
\hline Unknown/no answer & 8,135 & 3.2 & 4,832 & 59 \\
\hline \multicolumn{5}{|l|}{ Age, years } \\
\hline $12-17$ & 23,933 & 9.3 & 13,951 & 58 \\
\hline $18-29$ & 45,238 & 17.6 & 22,963 & 51 \\
\hline $30-39$ & 42,947 & 16.7 & 22,618 & 53 \\
\hline $40-49$ & 47,242 & 18.4 & 29,168 & 62 \\
\hline $50-59$ & 41,870 & 16.3 & 29,201 & 70 \\
\hline $60+$ & 56,109 & 21.8 & 44,855 & 80 \\
\hline \multicolumn{5}{|l|}{ Region } \\
\hline New England & 13,239 & 5.1 & 8,364 & 63 \\
\hline Middle Atlantic & 36,733 & 14.3 & 23,608 & 64 \\
\hline East North Central & 41,288 & 16.0 & 27,356 & 66 \\
\hline West North Central & 17,767 & 6.9 & 11,657 & 66 \\
\hline South Atlantic & 47,913 & 18.6 & 30,399 & 63 \\
\hline East South Central & 15,478 & 6.0 & 9,634 & 62 \\
\hline West South Central & 28,529 & 11.1 & 17,499 & 61 \\
\hline Pacific & 39,657 & 15.4 & 29,646 & 75 \\
\hline Mountain & 16,735 & 6.5 & 10,593 & 63 \\
\hline \multicolumn{5}{|l|}{ Population density } \\
\hline$<100,000$ & 35,545 & 13.8 & 22,873 & 64 \\
\hline $100,000-499,999$ & 43,231 & 16.8 & 26,997 & 62 \\
\hline $500,000-1,999,999$ & 57,711 & 22.4 & 36,572 & 63 \\
\hline $2,000,000+$ & 120,852 & 47.0 & 76,314 & 63 \\
\hline \multicolumn{5}{|l|}{ Household size } \\
\hline 1 Member & 31,876 & 12.4 & 22,428 & 70 \\
\hline 2 Members & 79,139 & 30.8 & 55,941 & 71 \\
\hline 3 Members & 48,903 & 19.0 & 29,848 & 61 \\
\hline 4 Members & 52,113 & 20.3 & 29,755 & 57 \\
\hline $5+$ Members & 45,308 & 17.6 & 24,784 & 55 \\
\hline \multicolumn{5}{|l|}{ Household income } \\
\hline$<\$ 22,500$ & 52,282 & 20.3 & 32,856 & 63 \\
\hline$\$ 22,500-39,999$ & 49,267 & 19.1 & 30,921 & 63 \\
\hline$\$ 40,000-59,999$ & 46,730 & 18.2 & 29,528 & 63 \\
\hline$\$ 60,000-89,999$ & 51,371 & 20.0 & 32,514 & 63 \\
\hline$\$ 90,000+$ & 57,689 & 22.4 & 36,937 & 64 \\
\hline
\end{tabular}


in the United States. We also compare the patterns of preventive migraine treatment found in the population with recommendations drawn by a panel of headache experts.

Methods. Sample and survey. The AMPP was modeled on the methods of the AMS-I and AMS-II. ${ }^{4,5}$ A validated selfadministered headache questionnaire was mailed in June 2004 to a stratified random sample of 120,000 US households, drawn from a 600,000-household nationwide panel maintained by the $\mathrm{Na}$ tional Family Opinion. The panel is comprised of sampling blocks, each with 5,000 households, which are constructed to be representative of the US population in terms of census region, population density, age of the head of the household, household income, and number of household members. Demographic and census information is obtained from each household during an initial recruitment mailing and routinely updated. Roughly $30 \%$ of each sampling block is updated or replaced every 2 years.

Initial screening questions were completed by the head of the household, who reported the total number of household members and the number of household members with at least occasional self-defined severe headache. Each household member with severe headaches was then asked to complete the remainder of the survey questions.

The validated questionnaire consisted of 21 questions assessing headache features. In addition, the survey included the Migraine Disability Assessment (MIDAS) questionnaire. ${ }^{17}$ MIDAS was used to divide patients into four grades using previously validated and well-accepted scores based on lost time due to headaches. Finally, the questionnaire assessed use of health care and treatments for migraine. A diagnosis of migraine was assigned based on the criteria proposed by the second edition of the International Classification of Headache Disorders (ICHD-2), which is identical to the migraine criteria of the first edition (ICHD-1). ${ }^{18,19}$ The survey had been previously shown to have a sensitivity of $100 \%$ and specificity of $82.3 \%$ for the diagnosis of migraine. ${ }^{4}$

Patterns of migraine preventive treatment. Participants were asked if they have ever taken prescription medication on a daily basis, to help prevent headache from occurring. Those who reported using preventive agents were asked whether they were currently taking such medications or when they stopped. Finally, subjects were asked about other medications they used on a daily basis from the following categories: water pills, other medications for high blood pressure, medications for seizure, medications for diabetes, medication for cholesterol, medication for diabetes, medications for depression, and medication for anxiety. Based on the responses, migraineurs were categorized as 1) never users of preventive medication; 2) current users; 3 ) previous users (had used preventive medications in the past, but were not currently); or 4) coincident users (reported medications for hypertension other than water pills, antiseizure medications, or prescription medications for depression). We recognize that this definition is overinclusive.

Candidates for migraine prevention. An expert panel of 12 physicians (neurologists and primary care doctors) as well as epidemiologists, psychologists, and statisticians with experience in headache research conducted several meetings in 2004 to develop guidelines for the use of preventive medication that could be operationalized in an epidemiologic study. Guidelines of the US Headache Consortium Guidelines were reviewed. ${ }^{12}$ The panel based its recommendations on headache days per month experienced by migraineurs, as well as the level of attack-related impairment caused by the headaches. Impairment during a headache attack was categorized as severe impairment (unable to function or requiring bed rest), some impairment (able to function, but with reduced performance), or no impairment (able to function normally).

Based on expert consensus and the evidence, three groups were defined.

1. Prevention should be offered: migraine subjects reporting either 6 or more headache days per month, 4 or more headache days with at least some impairment, or 3 or more headache days with severe impairment or requiring bed rest.

2. Prevention should be considered: migraineurs with 4 or $5 \mathrm{mi}-$ graine days per month with normal functioning, 3 migraine days with some impairment, or 2 migraine days with severe impairment.

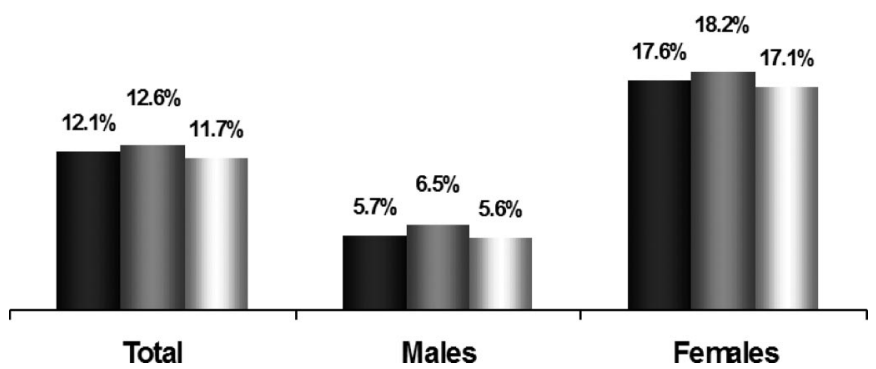

Figure 1. Prevalence of migraine in the American Migraine Study (AMS)-I, AMS-II, and American Migraine Prevalence and Prevention (AMPP) study for total sample and by sex.

3. Prevention is not indicated: migraineurs with less than 4 headache days per month and no impairment, or subjects with no more than 1 headache day per month regardless of the impairment.

Data analysis. Data from subjects aged 12 years and older were analyzed as previously described to estimate prevalence and variation in prevalence by demographic factors. ${ }^{3-5}$ Sex-specific prevalence estimates of migraine (1-year period prevalence) were derived by age, race, urban vs rural residence, household income, and region of the country. GLIM Poisson regression (log-linear models) was used to model sex- and age-specific prevalence by income and to derived adjusted prevalence ratios. Data were modeled separately by sex. Age was divided into five categories, beginning with age 20 to 24 years and continuing to age 75 to 79 years. Those aged 12 to 19 years and those aged 80 years or older were treated as separate categories, and all age groups were modeled as a continuous variable. Two race groups (black and white), four population density groups (less than $100,000,100,000$ to 499,999, 500,000 to $1,999,999$, and greater than or equal to $2,000,000$ ), five income groups (less than $\$ 22,500, \$ 22,500$ to $\$ 39,999, \$ 40,000$ to $\$ 59,999, \$ 60,000$ to $\$ 89,999$, and greater than or equal to $\$ 90,000$ ), and nine US regions (Mountain, New England, Middle Atlantic, South Atlantic, East North Central, West North Central, East South Central, West South Central, and Pacific) were defined.

Adjusted estimates. Sex-specific regression models were used to adjust for possible confounding of demographic variables in estimating prevalence. Among men, age $\left(\chi^{2}=957.95, d f=5, p<\right.$ $0.0001)$, income $\left(\chi^{2}=311.65, d f=4, p<0.0001\right)$, race $\left(\chi^{2}=\right.$ $19.65, d f=1, p<0.0001)$, geographic region $\left(\chi^{2}=53.01, d f=8\right.$, $p<0.0001)$, and population density $\left(\chi^{2}=71.85, d f=3, p<\right.$ 0.0001 ) improved the fit of the model to the data. Among women, age $\left(\chi^{2}=4,685.75, d f=5, p<0.0001\right)$, income $\left(\chi^{2}=324.23\right.$, $d f=4, p<0.0001)$, race $\left(\chi^{2}=57.20, d f=1, p<0.0001\right.$, geographic region $\left(\chi^{2}=149.70, d f=8, p<0.0001\right)$, and population density ( $\left.\chi^{2}=259.51, d f=3, p<0.0001\right)$ each improved the fit of the model to the data. All covariates were included in the final model to derive adjusted prevalence ratios by race, age, income, urban vs rural residence, and region.

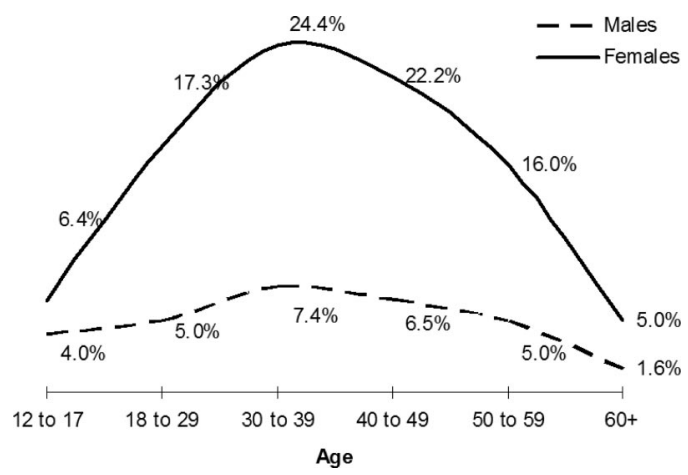

Figure 2. One-year period prevalence of migraine by age and sex adjusted for demographics. 


\begin{tabular}{|c|c|c|c|c|c|c|}
\hline & \multicolumn{2}{|c|}{ Prevalence, $\%$} & \multicolumn{4}{|c|}{ Crude and adjusted prevalence ratios* } \\
\hline & \multirow{2}{*}{$\frac{\text { Men }}{\text { Crude }}$} & \multirow{2}{*}{$\frac{\text { Women }}{\text { Crude }}$} & \multicolumn{2}{|c|}{ Men } & \multicolumn{2}{|c|}{ Women } \\
\hline & & & Crude & Adjusted & Crude & Adjusted \\
\hline \multicolumn{7}{|l|}{ Race } \\
\hline White & 5.7 & 17.3 & 1.00 & 1.00 & 1.00 & 1.00 \\
\hline Black & 4.1 & 13.7 & $0.73(0.63-0.84)$ & $0.62(0.54-0.71)$ & $0.79(0.74-0.84)$ & $0.69(0.65-0.73)$ \\
\hline \multicolumn{7}{|l|}{ Age, years } \\
\hline $12-17$ & 4.9 & 7.3 & 1.00 & 1.00 & 1.00 & 1.00 \\
\hline $18-29$ & 6.2 & 20.4 & $1.27(1.12-1.44)$ & $1.26(1.10-1.43)$ & $2.79(2.54-3.06)$ & $2.72(2.49-2.99)$ \\
\hline $30-39$ & 9.0 & 28.1 & $1.85(1.64-2.08)$ & $1.86(1.65-2.10)$ & $3.85(3.52-4.20)$ & $3.84(3.50-4.21)$ \\
\hline $40-49$ & 7.9 & 25.5 & $1.63(1.45-1.83)$ & $1.63(1.45-1.84)$ & $3.49(3.18-3.80)$ & $3.49(3.19-3.83)$ \\
\hline $50-59$ & 5.9 & 18.2 & $1.22(1.08-1.38)$ & $1.25(1.11-1.42)$ & $2.48(2.27-2.72)$ & $2.51(2.28-2.75)$ \\
\hline $60+$ & 2.1 & 6.4 & $0.44(0.38-0.50)$ & $0.40(0.34-0.46)$ & $0.87(0.79-0.96)$ & $0.78(0.71-0.87)$ \\
\hline \multicolumn{7}{|l|}{ Region } \\
\hline New England & 4.9 & 15.0 & 1.00 & 1.00 & 1.00 & 1.00 \\
\hline Middle Atlantic & 4.9 & 15.3 & $1.00(0.85-1.18)$ & $0.97(0.83-1.15)$ & $1.02(0.94-1.11)$ & $1.05(0.97-1.14)$ \\
\hline South Atlantic & 5.2 & 15.9 & $1.07(0.92-1.25)$ & $0.99(0.85-1.16)$ & $1.06(0.98-1.15)$ & $1.04(0.96-1.13)$ \\
\hline East North Central & 5.6 & 16.9 & $1.14(0.85-1.35)$ & $1.03(0.87-1.23)$ & $1.13(1.03-1.25)$ & $1.07(0.98-1.17)$ \\
\hline West North Central & 5.9 & 17.9 & $1.21(1.04-1.41)$ & $1.16(0.99-1.35)$ & $1.19(1.10-1.29)$ & $1.20(1.11-1.30)$ \\
\hline East South Central & 7.4 & 21.1 & $1.52(1.28-1.80)$ & $1.29(1.08-1.54)$ & $1.41(1.29-1.54)$ & $1.27(1.17-1.39)$ \\
\hline West South Central & 6.3 & 18.8 & $1.28(1.09-1.51)$ & $1.15(0.98-1.36)$ & $1.26(1.16-1.37)$ & $1.21(1.11-1.31)$ \\
\hline Pacific & 5.5 & 16.3 & $1.12(0.96-1.31)$ & $1.10(0.94-1.30)$ & $1.09(1.00-1.18)$ & $1.11(1.02-1.20)$ \\
\hline Mountain & 5.6 & 18.3 & $1.15(0.96-1.37)$ & $1.01(0.84-1.21)$ & $1.23(1.12-1.34)$ & $1.13(1.03-1.23)$ \\
\hline \multicolumn{7}{|l|}{ Population density } \\
\hline$<100,000$ & 6.6 & 20.0 & 1.00 & 1.00 & 1.00 & 1.00 \\
\hline $100,000-499,999$ & 6.4 & 19.2 & $0.98(0.89-1.08)$ & $1.03(0.93-1.13)$ & $0.96(0.91-1.01)$ & $0.99(0.95-1.04)$ \\
\hline $500,000-1,999,999$ & 6.0 & 18.0 & $0.91(0.83-1.00)$ & $1.03(0.93-1.13)$ & $0.90(0.86-0.94)$ & $0.97(0.93-1.02)$ \\
\hline $2,000,000+$ & 4.9 & 14.9 & $0.75(0.69-0.81)$ & $0.94(0.86-1.03)$ & $0.75(0.71-0.78)$ & $0.90(0.86-0.95)$ \\
\hline \multicolumn{7}{|l|}{ Household income } \\
\hline$<\$ 22,500$ & 8.8 & 20.1 & 1.00 & 1.00 & 1.00 & 1.00 \\
\hline$\$ 22,500-39,999$ & 5.5 & 18.2 & $0.62(0.57-0.68)$ & $0.62(0.57-0.68)$ & $0.91(0.87-0.94)$ & $0.82(0.79-0.86)$ \\
\hline$\$ 40,000-59,999$ & 5.3 & 17.2 & $0.59(0.55-0.65)$ & $0.55(0.50-0.61)$ & $0.86(0.82-0.90)$ & $0.73(0.69-0.76)$ \\
\hline$\$ 60,000-89,999$ & 5.1 & 15.9 & $0.58(0.53-0.63)$ & $0.52(0.47-0.57)$ & $0.79(0.75-0.83)$ & $0.64(0.61-0.67)$ \\
\hline$\$ 90,000+$ & 4.2 & 13.6 & $0.47(0.43-0.52)$ & $0.43(0.39-0.47)$ & $0.67(0.64-0.71)$ & $0.55(0.52-0.57)$ \\
\hline
\end{tabular}

* Adjusted for age, sex, race, region, population density, household income, and household size.

Results. A total of 120,000 households were contacted, encompassing 257,399 household members. Surveys were returned from 77,879 households (65\% response) yielding data for 162,576 household members aged 12 years or older. Response rates (table 1 ) were similar in men $(62 \%)$ and women $(64 \%)$ and were higher in white $(65 \%)$ than in black $(56 \%, p<0.001)$ individuals and in those aged older than 50 years $(p<0.01)$. Response rates did not differ significantly by geographic region, population density, or household income. In comparison to nonresponders, responders were older and more likely to be women. There were no differences by geographic region, population density, or household income.

Migraine prevalence. There were 18,968 individuals aged 12 years or older who met ICHD-2 criteria for mi- graine yielding an unadjusted 1-year period prevalence estimate of $11.7 \%$ (5.6\% for men and $17.1 \%$ for women; figure 1). Age-specific migraine prevalence curves adjusted for demographics are provided in figure 2. Migraine prevalence was highest in those aged 30 to 39 years for both men $(7.4 \%)$, and women $(24.4 \%)$. Prevalence was lowest in those aged 60 years or older at $1.6 \%$ in men and $5.0 \%$ in women. At the other end of the lifespan, prevalence was $4.0 \%$ in men and $6.4 \%$ in women aged between 12 and 17 years.

For both men and women (table 2), prevalence was significantly higher in whites than in blacks (women, $17.3 \%$ vs $13.7 \%$; men, $5.7 \%$ vs $4.1 \%$ ). Finally, for both sexes, the prevalence of migraine was higher in those of lower income. In those with a household income higher than 


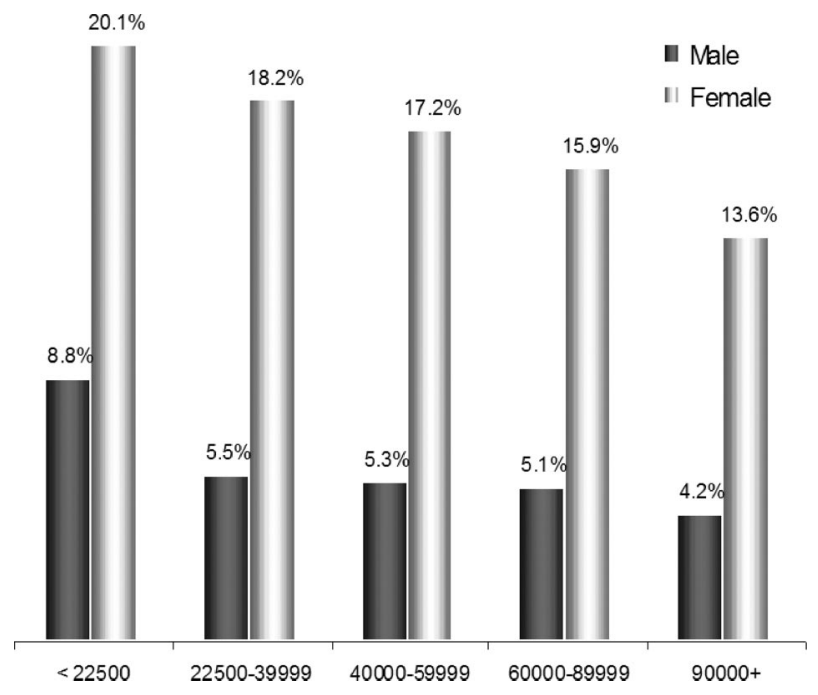

Figure 3. One-year period prevalence of migraine by sex and household income.

$\$ 90,000$, the prevalence of migraine was $13.6 \%$ in women and $4.2 \%$ in men. In those with an income lower than $\$ 22,500$, the prevalence was $20.1 \%$ in women and $8.8 \%$ in men (figure 3). After adjusting for other factors, the prevalence ratio for migraine was significantly lower with every increase in income strata, and in the highest stratum $(\$ 90,000+)$, prevalence was reduced by nearly half.

The majority of the migraineurs $(62.7 \%)$ had 1 to 4 headache days per month (table 3 ). During migraine attacks, most migraineurs reported severe impairment or the need for bed rest (53.7\%); just $7.2 \%$ reported no attackrelated impairment. During a 3-month period, $35.1 \%$ of the migraineurs had at least 1 day of activity restriction related to headache. Although most (63.7\%) were classified as MIDAS grade 1 (no or little migraine-related disability), $22 \%$ had moderate or severe disability levels (MIDAS grades 3 or 4 ).

Distribution of frequency and impairment. Table 4 provides the distribution of monthly headache frequency and attack-related impairment for those with migraine. As indicated by a single asterisk in table 4, prevention should be offered to approximately one quarter of the migraineurs (25.7\%). Of those, $60 \%$ have severe impairment or require bed rest. An additional $13.1 \%$ met criteria for considering preventive treatment.

Details on the use of migraine prevention among the individuals surveyed were described in a separate article. ${ }^{20}$ In brief, only $13 \%$ of the migraineurs were currently taking preventive medication for migraine. In our survey, $43.3 \%$ had never used a migraine preventive treatment, $25.5 \%$ were previous users, and $18 \%$ were coincident users. Among those who had never used a preventive, approximately one-third $(32.4 \%)$ met expert guideline criteria for offering it $(19.3 \%)$ or considering it $(13.1 \%)$. Women were more likely than men to need preventive therapy $(34.0 \%$ vs $27.5 \%$, chi $=30.7, p<0.001)$.

Discussion. Herein, we report on the prevalence and distribution of migraine in the United States. We then evaluate the frequency of headache attacks and migraine-related impairment as a prelude to evaluating indications for preventive treatment. In
Table 3 Migraine frequency and impact

\begin{tabular}{|c|c|}
\hline Variable & $\mathrm{n}(\%)$ \\
\hline \multicolumn{2}{|l|}{ Monthly headache frequency } \\
\hline$<1$ per month & $4,279(23.4)$ \\
\hline 1-4 per month & $11,481(62.7)$ \\
\hline 5-9 per month & $1,761(9.6)$ \\
\hline 9-14 per month & $777(4.2)$ \\
\hline \multicolumn{2}{|l|}{$\begin{array}{l}\text { Headache-related impairment during } \\
\text { severe headache }\end{array}$} \\
\hline Function normally & $1,366(7.2)$ \\
\hline Some impairment & $7,299(39.1)$ \\
\hline Severe impairment or bed rest required & $10,035(53.7)$ \\
\hline \multicolumn{2}{|l|}{ Days of activity restriction per headache } \\
\hline 0 & $3,113(16.8)$ \\
\hline$<1$ & $8,909(48.1)$ \\
\hline $1-2$ & $5,556(30.0)$ \\
\hline $3-5$ & $779(4.2)$ \\
\hline $6+$ & $171(0.9)$ \\
\hline \multicolumn{2}{|l|}{$\begin{array}{l}\text { School/work/social impact in previous } \\
3 \text { months }\end{array}$} \\
\hline Missed at least 1 day of work/school & $4,790(25.3)$ \\
\hline $\begin{array}{l}\text { Work/school productivity reduced by } \\
\text { at least } 50 \%\end{array}$ & $5,311(28.1)$ \\
\hline Did no household work & $9,050(47.7)$ \\
\hline $\begin{array}{l}\text { Household productivity reduced by } \\
\text { at least } 50 \%\end{array}$ & $6,512(34.3)$ \\
\hline Missed family or social activity & $5,519(29.1)$ \\
\hline \multicolumn{2}{|l|}{ MIDAS grade } \\
\hline 1 & $12,078(63.7)$ \\
\hline 2 & $2,719(14.3)$ \\
\hline 3 & $2,032(10.7)$ \\
\hline 4 & $2,139(11.3)$ \\
\hline
\end{tabular}

MIDAS = Migraine Disability Assessment

this study, the 1-year period prevalence of migraine was $17.1 \%$ in women and $5.6 \%$ in men.

Based on a report from the US Centers for Disease Control and Prevention, it was suggested that the prevalence of migraine in the United States increased by $60 \%$, from 25.8 per 1,000 person-years to 41 per 1,000 person-years between 1981 and $1989 .{ }^{21}$ A study of migraine prevalence based on medical record review also suggested that migraine prevalence was increasing. ${ }^{22}$ Three methodologically identical studies during a 15-year period with samples of more than 20,000 (AMS-I), 30,000 (AMS-II), and 160,000 (AMPP) demonstrate that migraine prevalence has been stable in the United States. Studies that rely on self-report or medical record review may reflect increasing awareness, consultation, and diagnosis of migraine, rather than changing prevalence.

Our study confirms major findings of the AMS-I and AMS-II. ${ }^{3-5}$ In all three studies, migraine prevalence was higher in whites than in blacks. There was 
Table 4 Distribution of headache frequency and attack-related impairment, and corresponding prevention need based on headache expert recommendations

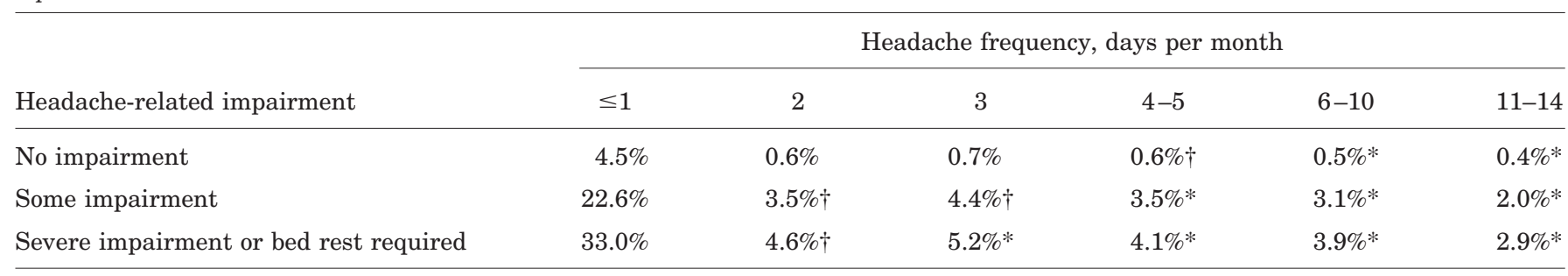

* Panel of experts recommended offering migraine prevention $(25.7 \%)$.

$\dagger$ Panel of experts recommended considering migraine prevention (13.1\%).

also a striking inverse relation between family income and migraine prevalence. All three studies report a three-to-one women preponderance.

Like earlier studies in the United States, most migraineurs had from one to four headache attacks per month. ${ }^{3-6}$ Our study also confirms the burden of migraine in the population and shows that more than $50 \%$ of all migraineurs report severe impairment or require bed rest during their headaches. There is no evidence that migraine severity or attack frequency has increased.

Nonetheless, attack frequency and impairment are part of the public health burden of migraine and are potential targets for treatment. Attack-related impairment can be addressed with acute treatment, whereas attack frequency is best addressed with behavioral methods and preventive pharmacotherapy. To assess the need for preventive therapy, an expert panel developed operational criteria for offering or considering prevention based on headache frequency and attack-related disability.

The criteria applied for "offer" or "consider" preventive treatment are intended as an operational rule for epidemiologic research and not as a clinical management guideline. They were admittedly somewhat arbitrary. In practice, the decision to prescribe a preventive therapy is multifactorial and depends on previous treatment history, patient preference, comorbidities, and a range of other factors. Therefore, the criteria presented in table 4 are incomplete. For those who want to use different criteria to assess the need for prevention, we provided a detailed breakdown of patients (table 4). We acknowledge that there are patients in the "offer prevention" group who might be well-managed by modifying acute treatment, and there are patients with infrequent severe attacks, perhaps with persistent neurologic deficits, who may be best treated with a preventive. It is not possible to operationalize the complex dialogue and judgment for prevention in this study. These data are intended only to provide a benchmark.

With these caveats, we found that a sizeable subset of patients meeting criteria for offering $(25.7 \%)$ or considering (13.1\%) preventive therapy do not receive it. The proportion of subjects who were candidates for or should be considered for preventative treatment was $38.8 \%$. Only $12.4 \%$ of the migraineurs currently used a preventative, indicating that this form of treatment is underutilized. Comparable data are not available from population studies in the United States.

Use of preventive treatment varies with region of the world. Although the disability of migraine in the United States, France, and Latin America is similar, just $6 \%$ of the migraineurs in France and 2\% in Latin America were current preventive users..$^{23,24}$

Our study has limitations. First, we used a validated questionnaire to diagnose migraine just in those with self-defined severe headaches. However, migraine attacks do not have to be severe. Limits of our criteria for migraine prevention were discussed above. Second, our definition of coincident users of preventive medication is overly broad. We assume that antihypertensive treatments (other than diuretics), antiepileptic medications, and antidepressant drugs have antimigraine properties, which may not necessarily be true. For example, individuals taking beta blockers, calcium channel blockers, lisinopril, and candesartan, as well as persons using antihypertensive treatments not tested for migraine, are in the coincident category. As a consequence, our coincident category provides an upper-boundary estimate in the number of individuals using medications potentially effective for migraine. Another limitation is that information on nutraceutical medications such as magnesium and vitamin $B_{2}$ was not captured in the screening questionnaire. In the AMPP follow-up study, we plan to capture details of medication and nutraceutical use. Strengths of this study include the size of the sample, its representativeness of the US population regarding demographic characteristics, and the use of questionnaires that allow comparisons with the AMS-I and AMS-II. ${ }^{3-6}$

\section{Acknowledgment}

The authors thank Suzanne Simons of the National Headache Foundation; Kristina M. Fanning, PhD; Kathy Ward; and Daniel Serrano for help with data management and statistical analyses.

\section{References}

1. Scher AI, Stewart WF, Lipton RB. Migraine and headache: a metaanalytic approach. In: Crombie IK, ed. Epidemiology of pain. Seattle: IASP Press, 1999:159-170.

2. Rasmussen BK. Epidemiology of headache. Cephalalgia 1995;15:45-68.

3. Lipton RB, Stewart WF, Simon D. Medical consultation for migraine: results from the American Migraine Study. Headache 1998;38:87-96. 
4. Lipton RB, Stewart WF, Diamond S, Diamond ML, Reed M. Prevalence and burden of migraine in the United States: data from the American Migraine Study II. Headache 2001;41:646-657.

5. Lipton RB, Diamond S, Reed M, Diamond ML, Stewart WF. Migraine diagnosis and treatment: results from the American Migraine Study II. Headache 2001;41:638-645.

6. Ferrari MD. The economic burden of migraine to society. Pharmacoeconomics 1998;13:667-676.

7. Stewart WF, Lipton RB, Simon D. Work-related disability: results from the American Migraine study. Cephalalgia 1996;16:231-238.

8. Michel P, Dartigues JF, Lindousli A, Henry P. Loss of productivity and quality of life in migraineurs among French workers: results from the GAZEL cohort. Headache 1997;37:71-78.

9. Edmeads J, Findlay H, Tugwell P, Pryse-Phillips W, Nelson RF, Murray $\mathrm{TJ}$. Impact of migraine and tension-type headache on life-style, consulting behavior, and medication use: a Canadian population survey. Can J Neurol Sci 1993;20:131-137.

10. Edmeads J, Mackell JA. The economic impact of migraine: an analysis of direct and indirect costs. Headache 2002;42:501-509.

11. $\mathrm{Hu} \mathrm{XH}$, Markson LE, Lipton RB, Stewart WF, Berger ML. Burden of migraine in the United States: disability and economic costs. Arch Intern Med 1999;159:813-818.

12. Silberstein SD, Rosenberg J. Multispecialty consensus on diagnosis and treatment of headache. Neurology 2000;54:1553.

13. Scher AI, Stewart WF, Ricci JA, Lipton RB. Factors associated with the onset and remission of chronic daily headache in a population-based study. Pain 2003;106:81-89.

14. Katsarava Z, Schneeweiss S, Kurth T, et al. Incidence and predictors for chronicity of headache in patients with episodic migraine. Neurology 2004;62:788-790.
15. Kruit MC, van Buchem MA, Hofman PA, et al. Migraine as a risk factor for subclinical brain lesions. JAMA 2004;291:427-434.

16. Lipton RB, Pan J. Is migraine a progressive brain disease? JAMA 2004;291:493-494.

17. Stewart WF, Lipton RB, Dowson AJ, Sawyer J. Development and testing of the Migraine Disability Assessment (MIDAS) Questionnaire to assess headache-related disability. Neurology 2001;56 (suppl 1):S20 S28.

18. Headache Classification Committee of the International Headache Society. Classification and diagnostic criteria for headache disorders, cranial neuralgias and facial pain. Cephalalgia 1988;8 (suppl 7):1-96.

19. Headache Classification Subcommittee of the International Headache Society. The International Classification of Headache Disorders, ed. 2. Cephalgia 2004;24 (suppl 1):1-15.

20. Diamond S, Silberstein S, Loder E, Reed M, Bigal ME, Lipton RB. Patterns of diagnosis and acute and preventive treatment of migraine in the United States: results of the American Migraine Prevalence and Prevention Study. Headache 2006 (in press).

21. Centers for Disease Control and Prevention. Prevalence of chronic migraine headaches: United States, 1980-89. MMWR Morb Mortal Wkly Rep 1991; 40:331-332.

22. Stang PE, Yanagihara T, Swanson JW, et al. Incidence of migraine headaches: a population-based study in Olmsted County, Minnesota. Neurology 1992;42:1657-1662.

23. Lucas C, Chaffaut C, Artaz MA, Lanteri-Minet M. FRAMIG 2000: medical and therapeutic management of migraine in France. Cephalalgia 2005;25:267-279.

24. Morillo LE, Alarcon F, Aranaga N, et al. Clinical characteristics and patterns of medication use of migraneurs in Latin America from 12 cities in 6 countries. Headache 2005;45:118-126.

\section{P WWW.NEUROLOGY.ORG OFFERS IMPORTANT INFORMATION TO PATIENTS AND THEIR FAMILIES}

The Neurology Patient Page provides:

- a critical review of ground-breaking discoveries in neurologic research that are written especially for patients and their families

— up-to-date patient information about many neurologic diseases

- links to additional information resources for neurologic patients.

All Neurology Patient Page articles can be easily downloaded and printed, and may be reproduced to distribute for educational purposes. Click on the Patient Page icon on the home page (www.neurology.org) for a complete index of Patient Pages. 


\section{Neurology}

Migraine prevalence, disease burden, and the need for preventive therapy

R. B. Lipton, M. E. Bigal, M. Diamond, et al.

Neurology 2007;68;343-349

DOI 10.1212/01.wnl.0000252808.97649.21

\section{This information is current as of January 29, 2007}

\section{Updated Information \& Services}

Supplementary Material

\section{References}

\section{Citations}

Subspecialty Collections

Permissions \& Licensing

Reprints including high resolution figures, can be found at: http://n.neurology.org/content/68/5/343.full

Supplementary material can be found at: http://n.neurology.org/content/suppl/2009/08/27/68.5.343.DC2 http://n.neurology.org/content/suppl/2007/07/27/68.5.343.DC1

This article cites 21 articles, 4 of which you can access for free at: http://n.neurology.org/content/68/5/343.full\#ref-list-1

This article has been cited by 60 HighWire-hosted articles: http://n.neurology.org/content/68/5/343.full\#\#otherarticles

This article, along with others on similar topics, appears in the following collection(s):

All epidemiology

http://n.neurology.org/cgi/collection/all_epidemiology

Migraine

http://n.neurology.org/cgi/collection/migraine

Prevalence studies

http://n.neurology.org/cgi/collection/prevalence_studies

Information about reproducing this article in parts (figures,tables) or in its entirety can be found online at:

http://www.neurology.org/about/about_the_journal\#permissions

Information about ordering reprints can be found online:

http://n.neurology.org/subscribers/advertise

Neurology ${ }^{\circledR}$ is the official journal of the American Academy of Neurology. Published continuously since 1951, it is now a weekly with 48 issues per year. Copyright . All rights reserved. Print ISSN: 0028-3878. Online ISSN: 1526-632X.

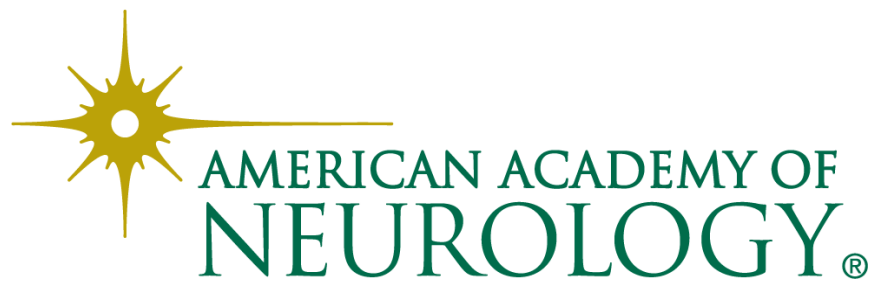

